\title{
Article \\ Halogen-Bond Mediated [2+2] Photodimerizations: À la Carte Access to Unsymmetrical Cyclobutanes in the Solid State
}

\author{
Jay Quentin ${ }^{1}\left(\mathbb{D}\right.$, Eric W. Reinheimer ${ }^{2}$ and Leonard R. MacGillivray ${ }^{1, *(\mathbb{D})}$ \\ 1 Department of Chemistry, University of Iowa, Iowa City, IA 52242, USA; jay-bell@uiowa.edu \\ 2 Rigaku Americas Corporation, 9009 New Trails Drive, The Woodlands, TX 77381, USA; \\ eric.reinheimer@rigaku.com \\ * Correspondence: len-macgillivray@uiowa.edu
}

check for

updates

Citation: Quentin, J.; Reinheimer, E.W.; MacGillivray, L.R.

Halogen-Bond Mediated [2+2]

Photodimerizations: À la Carte

Access to Unsymmetrical

Cyclobutanes in the Solid State.

Molecules 2022, 27, 1048. https://

doi.org/10.3390/molecules27031048

Academic Editor: Victor Mamane

Received: 27 December 2021

Accepted: 25 January 2022

Published: 3 February 2022

Publisher's Note: MDPI stays neutral with regard to jurisdictional claims in published maps and institutional affiliations.

Copyright: (C) 2022 by the authors. Licensee MDPI, Basel, Switzerland. This article is an open access article distributed under the terms and conditions of the Creative Commons Attribution (CC BY) license (https:// creativecommons.org/licenses/by/ $4.0 /)$.

\begin{abstract}
The ditopic halogen-bond (X-bond) donors 1,2-, 1,3-, and 1,4-diiodotetrafluorobenzene (1,2-, 1,3-, and 1,4-di-I-tFb, respectively) form binary cocrystals with the unsymmetrical ditopic X-bond acceptor trans-1-(2-pyridyl)-2-(4-pyridyl)ethylene (2,4-bpe). The components of each cocrystal (1,2-

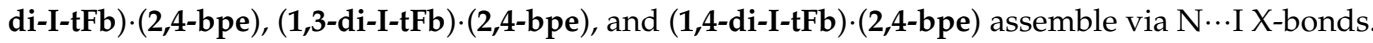
For (1,2-di-I-tFb) $\cdot(2,4-b p e)$ and (1,3-di-I-tFb) $(2,4-b p e)$, the $X$-bond donor supports the $C=C$ bonds of 2,4-bpe to undergo a topochemical [2+2] photodimerization in the solid state: UV-irradiation of each solid resulted in stereospecific, regiospecific, and quantitative photodimerization of 2,4-bpe to the corresponding head-to-tail $(h t)$ or head-to-head $(h h)$ cyclobutane photoproduct, respectively.
\end{abstract}

Keywords: cocrystal; crystal engineering; halogen bonding; photodimerization; cyclobutane

\section{Introduction}

Cyclobutane rings appended with $n$-pyridyl ( $n=2,3$ or 4$)$ (pyr) groups are useful building blocks to construct metal-organic assemblies and materials [1-4]. Many such molecules have been accessed via template-directed, topochemical [2+2] photodimerizations of alkenes within cocrystals. These transformations are conducted in the organic solid state and consequently, due to the highly ordered environment characteristic of crystalline reaction media, often proceed stereospecifically and quantitatively. Of particular and recent interest to our group have been cyclobutanes derived from photodimerization of unsymmetrical alkenes. These photoproducts are appended with two pairs of differently substituted pyr groups. Head-to-head $(h h)$ and head-to-tail $(h t)$ regioisomers are possible from photodimerizations of unsymmetrical alkenes [5]. Given that covalent-bond-forming reactions performed in the solid state are extremely sensitive to molecular packing, it is imperative to identify diverse and robust classes of template molecules capable of directing photodimerizations in crystals.

Herein, we report a series of binary cocrystals comprising components that selfassemble via N...I X-bonds. We show that in two of these cocrystals, the ditopic X-bond donor serves to support nearest-neighbor unsymmetrical alkenes (the X-bond acceptors) in a geometry conducive to topochemical [2+2] photodimerization in the solid state. Evidence is rapidly emerging that demonstrates $X$-bonds as useful supramolecular synthons in cocrystals to support [2+2] photodimerizations of alkenes appended with pyr groups. Whereas there are several examples of photodimerizations of symmetrical alkenes mediated by X-bonds [6-11], we are aware of only one example - as reported by Groeneman [12] - wherein an unsymmetrical alkene is assembled to react via X-bonds. We report on the single-crystal X-ray structures of the binary cocrystals $(\mathbf{1}, n$-di-I-tFb) $(\mathbf{2}, 4-\mathbf{b p e})(n=2,3$ or 4$)$, 2(1,2-di-I-tFb) $\cdot(\boldsymbol{h t}$-2, $\mathbf{4}-\mathrm{tpcb})$, and 2(1,3-di-I-tFb) $\cdot(\boldsymbol{h} \boldsymbol{h}-\mathbf{2}, \mathbf{4}-\mathrm{tpcb})$ (Scheme 1) with components

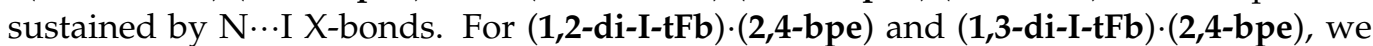
show the unsymmetrical alkene to generate the regioisomers $r c t t-1,3-b i s(2-p y r i d y l)-2,4-b i s(4-$ pyridyl)cyclobutane ( $h t$-2,4-tpcb) and $r c t t-1,2-b i s(2-p y r i d y l)-3,4-b i s(4-p y r i d y l) c y c l o b u t a n e$ 
(hh-2,4-tpcb), respectively, stereospecifically, regiospecifically, and in quantitative conversion (Scheme 2).

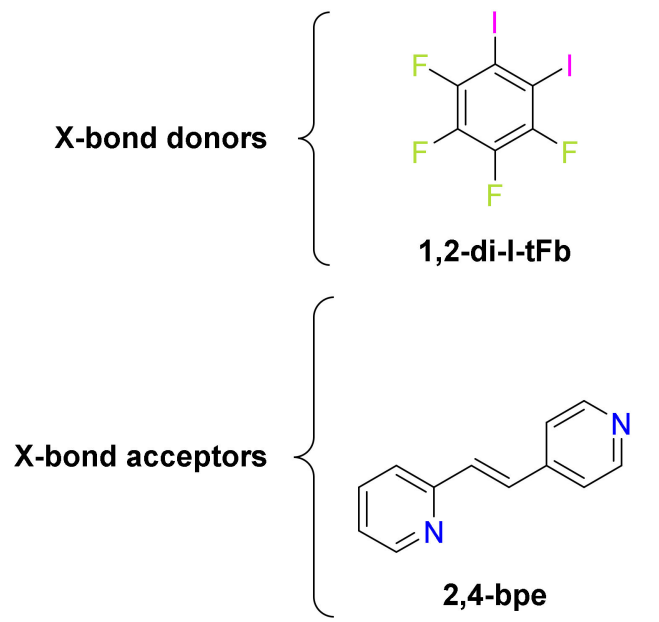

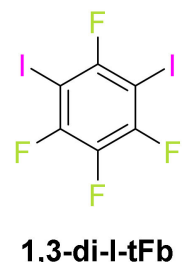<smiles>[R16][Y6](=O)O[Na]</smiles><smiles>Fc1c(F)c(I)c(F)c(I)c1F</smiles>

1,4-di-I-tFb

Scheme 1. Ditopic components for cocrystals and photoproducts.

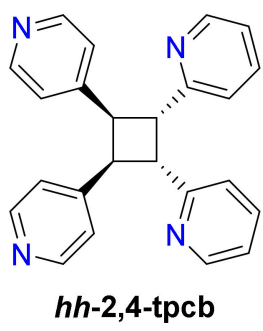<smiles>Fc1c(F)c(C=Cc2ccnc(C=Cc3cccnc3)c2)c(I)c(I)c1I</smiles>

$(1,2-d i-I-t F b) \cdot(2,4-b p e)$

\section{$100 \mathrm{~h}$, quantitative conversion}<smiles>CCC1CCCCC1C</smiles>

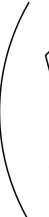<smiles>c1ccc([C@@H]2[C@@H](c3ccncc3)[C@@H](c3ccncc3)[C@H]2c2ccccn2)nc1</smiles>

2(1,2-di-I-tFb) (ht-2,4-tpcb) single diastereomer single regioisomer<smiles>Fc1c(F)c(C=Cc2ccnc(C=Cc3cccnc3)c2)c(I)c(F)c1I</smiles>

(1,3-di-I-tFb) $(2,4-b p e)$

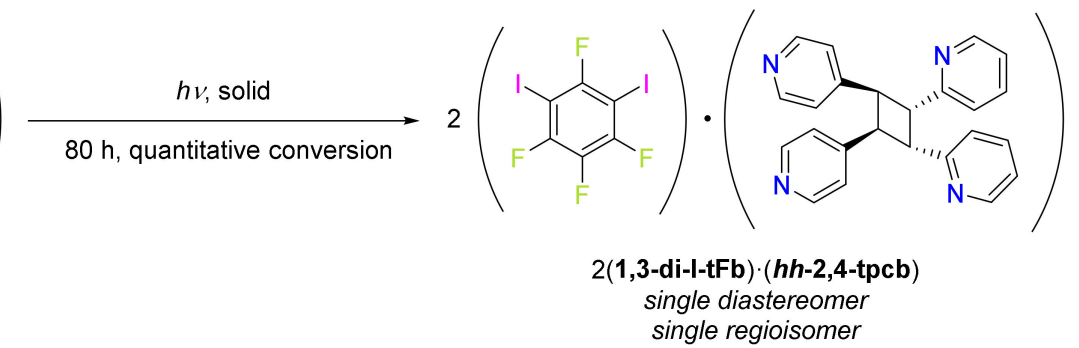

Scheme 2. UV-irradiation of (1,2-di-I-tFb) $($ 2,4-bpe $)$ or (1,3-di-I-tFb) (2,4-bpe) generates either $h t$ - or hh-2,4-tpcb, respectively.

\section{Results and Discussion}

Work by our group has demonstrated that the unsymmetrical cyclobutanes rctt-bis $(n$ pyridyl)-bis $\left(n^{\prime}\right.$-pyridyl)cyclobutanes $\left(n \neq n^{\prime}, n=2\right.$ or $4, n^{\prime}=2$ or 4$)$ can be constructed in the solid state by way of hydrogen-bond (H-bond) mediated self-assembly. The photoproducts were generated using ditopic H-bond donor coformers in binary cocrystals. Cyclobutanes with the pyr substituents in both $h t$ - [13] and $h$ h-regiochemistries [14] were obtained via infinite and discrete $\mathrm{H}$-bonded assemblies, respectively. While $\mathrm{H}$ - and $\mathrm{X}$ - bonds often display similar structural effects in the solid state (i.e., strength, directionality), the donor moieties (e.g., hydroxyl versus halogen) exhibit very different chemical properties, which can impact processes that follow the solid-state reactions (e.g., separations of photoproducts) [15].

\subsection{X-ray Crystal Structure of (1,2-di-I-tFb)·(2,4-bpe)}

The components of $(\mathbf{1}, \mathbf{2}-\mathbf{d i}-\mathbf{I}-\mathbf{t F b}) \cdot(\mathbf{2}, \mathbf{4}-\mathbf{b p e})$ crystallize in the triclinic space group $P \overline{1}$ (Figure 1, Table 1). The asymmetric unit consists of two unique molecules each of 
1,2-di-I-tFb and 2,4-bpe (Figure 1a). The pyr rings of the two molecules of 2,4-bpe lie approximately coplanar and exhibit different twist angles $\left(\phi \sim 3.4^{\circ}\right.$ for $\operatorname{pyr}_{\mathrm{N} 1 / \mathrm{N} 2}, \phi \sim 8.0^{\circ}$ for $\mathrm{pyr}_{\mathrm{N} 3 / \mathrm{N} 4}$, Table 2). The components of the cocrystal interact primarily via $\mathrm{N} \cdots \mathrm{I}$ X-bonds $(d(\mathrm{~N} 1 \cdots \mathrm{I} 1)=2.808(2) \AA ; d(\mathrm{~N} 2 \cdots \mathrm{I} 4)=3.147(2) \AA ; d(\mathrm{~N} 3 \cdots \mathrm{I} 3)=2.814(2) \AA) ; d(\mathrm{~N} 4 \cdots \mathrm{I} 2)=3.054(2)$ $\AA$, Table 3$)$, as well as secondary C-H $\cdots$ F forces $(d(\mathrm{H} 18 \cdots \mathrm{I} 2) \sim 2.98 \AA$; $d(\mathrm{H} 6 \cdots \mathrm{I} 4) \sim 2.98 \AA$ ) . Because of the arrangement, the components form 1D tapes $(\lambda \sim 2.52 \mathrm{~nm})$ along a diagonal within the crystallographic $b c$-plane (Figure $1 b$, Table 4). Adjacent chains run parallel and exhibit a tongue-in-groove fit manifested approximately along the crystallographic $b$-axis to give a corrugated, 2D, layered structure (Figure 1c, Table 4). Chains within adjacent layers run antiparallel. Alkenes between layers stack face-to-face and antiparallel $(h t)$ with nearest-neighbor $\mathrm{C}=\mathrm{C}$ bonds of 2,4'-bpe separated by $3.80 \AA$ [N1/N2] and $3.72 \AA$ [N3/N4] (Figure 1d). Both arrangements conform to the criteria of Schmidt [16] for topochemical [2+2] photodimerization.

a)

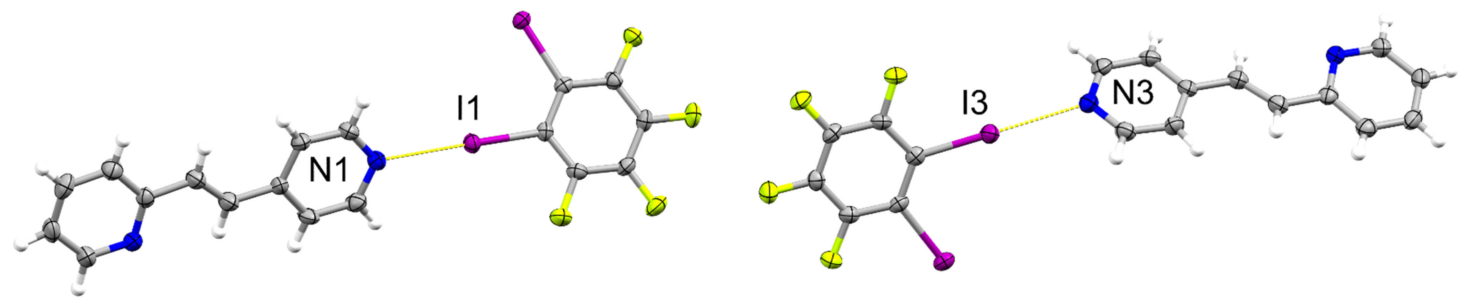

b)

A

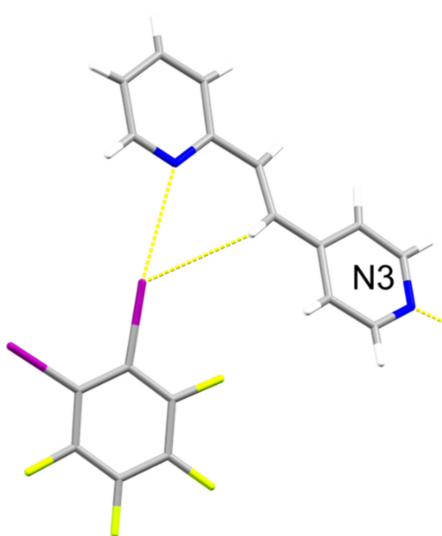

A'

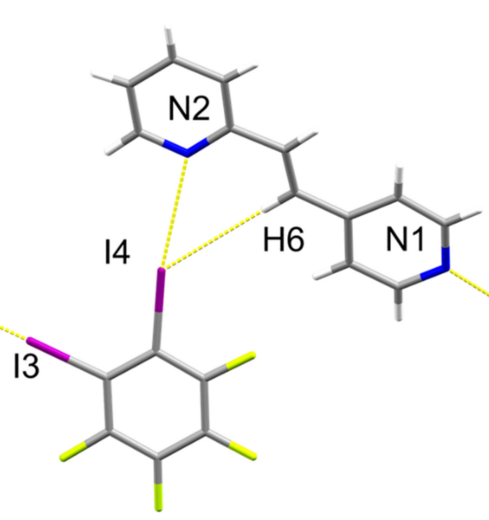

A

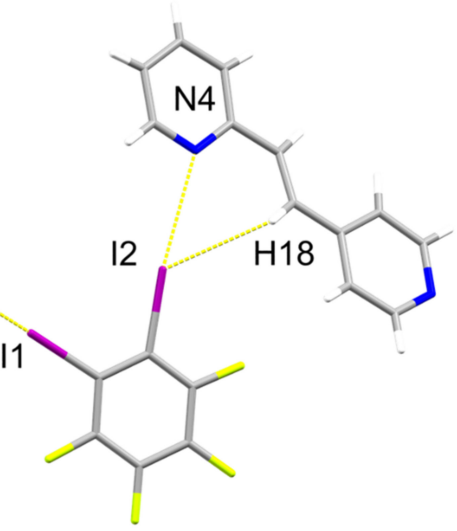

$\lambda \sim 2.52 \mathrm{~nm}$

c)

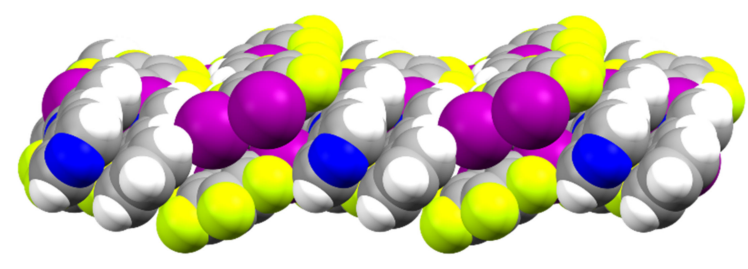

Figure 1. Cont. 
d)

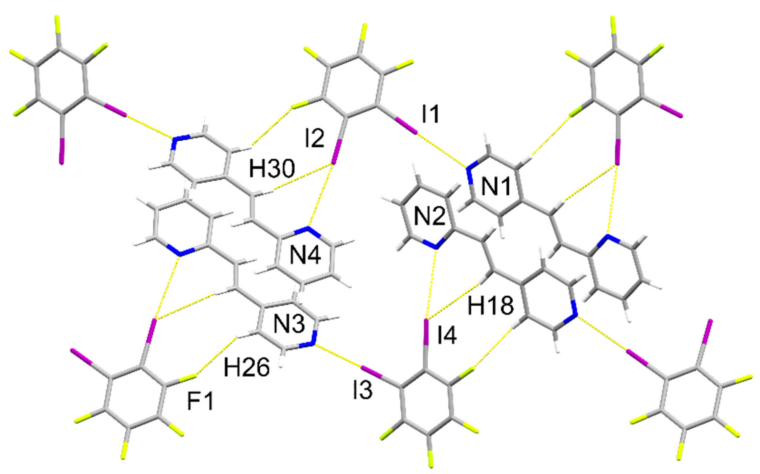

Figure 1. Perspectives of (1,2-di-I-tFb)·(2,4-bpe): (a) asymmetric unit (anisotropic displacement ellipsoids at 50\% probability; view along a); (b) 1D tapes illustrating $\mathrm{ABA}^{\prime} \mathrm{B}^{\prime}$ repeat motif (view along a); (c) corrugated layered structure (space-filling); and (d) reactive arrangement of nearest-neighbor alkene pairs.

Table 1. Crystallographic data and structure refinement statistics *.

\begin{tabular}{|c|c|c|}
\hline Cocrystal & $(1,2-d i-I-t F b) \cdot(2,4-b p e)$ & $2(1,2-\mathrm{di}-\mathrm{I}-\mathrm{tFb}) \cdot(h t-2,4-\mathrm{tpcb})$ \\
\hline CCDC deposition number & 2104746 & 2114529 \\
\hline Empirical formula & $\mathrm{C}_{18} \mathrm{H}_{10} \mathrm{~F}_{4} \mathrm{I}_{2} \mathrm{~N}_{2}$ & $\mathrm{C}_{36} \mathrm{H}_{20} \mathrm{~F}_{8} \mathrm{I}_{4} \mathrm{~N}_{4}$ \\
\hline Formula weight $/ \mathrm{g} \cdot \mathrm{mol}^{-1}$ & 584.08 & 1168.16 \\
\hline Temperature/K & $150(2)$ & $150(2)$ \\
\hline Crystal system & Triclinic & Triclinic \\
\hline Space group & $P-1$ & $P-1$ \\
\hline$a / \AA$ & $7.5879(8)$ & $9.1499(10)$ \\
\hline$b / \AA$ & 13.1862(13) & $10.6011(11)$ \\
\hline$c / \AA$ & $19.2918(19)$ & $10.9421(12)$ \\
\hline$\alpha /{ }^{\circ}$ & $80.092(5)$ & $62.054(5)$ \\
\hline$\beta /{ }^{\circ}$ & $89.530(5)$ & $77.014(5)$ \\
\hline$\gamma /{ }^{\circ}$ & $74.125(5)$ & $76.828(5)$ \\
\hline Volume $/ \AA^{3}$ & $1827.4(3)$ & 904.32(17) \\
\hline $\mathrm{Z}$ & 4 & 1 \\
\hline$\rho_{\text {calc }} / \mathrm{g} \cdot \mathrm{cm}^{-3}$ & 2.12 & 2.15 \\
\hline$\mu / \mathrm{mm}^{-1}$ & 3.484 & 3.521 \\
\hline$F(000)$ & 1096 & 548 \\
\hline Crystal size $/ \mathrm{mm}^{3}$ & $0.11 \times 0.06 \times 0.03$ & $0.10 \times 0.09 \times 0.06$ \\
\hline Radiation & $\operatorname{MoK} \alpha(\lambda=0.71073)$ & $\operatorname{MoK} \alpha(\lambda=0.71073)$ \\
\hline $2 \Theta$ range for data collection $/^{\circ}$ & 4.21 to 50.25 & 4.25 -to 50.25 \\
\hline Index ranges & $-9 \leq \mathrm{h} \leq 9,-15 \leq \mathrm{k} \leq 15,-23 \leq 1 \leq 21$ & $-10 \leq \mathrm{h} \leq 10,-12 \leq \mathrm{k} \leq 12,-13 \leq 1 \leq 13$ \\
\hline Reflections collected & $\overline{43105}$ & 40307 \\
\hline Independent reflections & $6502\left[R_{\mathrm{int}}=0.0349, R_{\mathrm{sigma}}=0.0229\right]$ & $3220\left[R_{\mathrm{int}}=0.0830, R_{\mathrm{sigma}}=0.0312\right]$ \\
\hline Data/restraints/parameters & $6502 / 0 / 549$ & $3220 / 0 / 235$ \\
\hline Goodness-of-fit on $F^{2}$ & 1.066 & 1.060 \\
\hline Final $R$ indices $[I \geq 2 \sigma(I)]$ & $R_{1}=0.0170$ & $R_{1}=0.0358$ \\
\hline \multirow{3}{*}{$R$ indices (all data) } & $w R_{2}=0.0363$ & $w R_{2}=0.0781$ \\
\hline & $R_{1}=0.0211$ & $R_{1}=0.0377$ \\
\hline & $w R_{2}=0.0379$ & $w R_{2}=0.0790$ \\
\hline Largest diff. peak/hole $/ \mathrm{e} \cdot \AA^{-3}$ & $0.66 /-0.36$ & $2.44 /-0.94$ \\
\hline
\end{tabular}

\footnotetext{
${ }^{*} R_{1}=\sum|| F_{\mathrm{o}}|-| F_{\mathrm{c}}|| / \sum\left|F_{\mathrm{o}}\right|, w R_{2}=\left[\sum w\left(F_{\mathrm{o}}^{2}-F_{\mathrm{c}}^{2}\right)^{2}\right] / \sum\left[w\left(F_{\mathrm{o}}^{2}\right)^{2}\right]^{1 / 2}$. Goodness-of-fit on $\mathrm{F}^{2}=\left[\sum w\left(\left|F_{\mathrm{o}}\right|-\left|F_{\mathrm{c}}\right|\right)^{2}\right.$ $/\left(N_{\text {obs }}-N_{\text {parameter }}\right)^{1 / 2}$.
} 
Table 2. Twist angles $(\phi)$ of pyr rings of 2,4-bpe in binary cocrystals.

\begin{tabular}{|c|c|c|}
\hline Crystal & 2,4-bpe Molecule & Twist Angle $\phi /^{\circ}$ \\
\hline \multirow[t]{2}{*}{$(1,2-d i-I-t F b) \cdot(2,4-b p e)$} & $\mathrm{N} 1 / \mathrm{N} 2$ & 3.4 \\
\hline & N3/N4 & 8.0 \\
\hline$(1,3-d i-I-t F b) \cdot(2,4-b p e)$ & N1/N2 & 3.8 \\
\hline$(1,4-d i-I-t F b) \cdot(2,4-b p e)$ & N1/N2 & 9.9 \\
\hline
\end{tabular}

Table 3. X-bond metrics for cocrystals.

\begin{tabular}{|c|c|c|c|c|c|c|}
\hline Cocrystal & X-Bond & $\begin{array}{c}\text { Pyridyl } \\
\text { Substitution }\end{array}$ & $d(\mathbf{N} \cdots \mathbf{I}) / \AA$ & $\Theta(C-I \cdots N) /^{\circ}$ & X-Bond Type & prs * \\
\hline \multirow[t]{4}{*}{$(1,2-d i-I-t F b) \cdot(2,4-b p e)$} & $\mathrm{I} 1 \cdots \mathrm{N} 1$ & 4 & $2.808(2)$ & 176.6 & I & 20 \\
\hline & $\mathrm{I} 2 \cdots \mathrm{N} 4$ & 2 & $3.054(2)$ & 174.0 & I & 13 \\
\hline & $\mathrm{I} 3 \cdots \mathrm{N} 3$ & 4 & $2.814(2)$ & 176.8 & I & 20 \\
\hline & $\mathrm{I} 4 \cdots \mathrm{N} 2$ & 2 & $3.147(2)$ & 171.9 & I & 11 \\
\hline \multirow[t]{2}{*}{$2(1,2-d i-I-t F b) \cdot(h t-2,4-t p c b)$} & $\mathrm{I} 1 \cdots \mathrm{N} 1$ & 4 & $2.946(4)$ & 172.6 & I & 17 \\
\hline & $\mathrm{I} 2 \cdots \mathrm{N} 2$ & 2 & $3.022(4)$ & 172.1 & I & 14 \\
\hline \multirow[t]{2}{*}{$(1,3-\mathrm{di}-\mathrm{I}-\mathrm{tFb}) \cdot(2,4-\mathrm{bpe})$} & $\mathrm{I} 1 \cdots \mathrm{N} 1$ & 4 & $2.795(4)$ & 177.2 & I & 21 \\
\hline & $\mathrm{I} 2 \cdots \mathrm{N} 2$ & 2 & $2.926(4)$ & 171.8 & I & 17 \\
\hline \multirow[t]{3}{*}{$2(1,3-\mathrm{di}-\mathrm{I}-\mathrm{tFb}) \cdot(h h-2,4-\mathrm{tpcb})$} & $\mathrm{I} 1 \cdots \mathrm{N} 1$ & 4 & $2.826(2)$ & 174.4 & I & 20 \\
\hline & $\mathrm{I} 2 \cdots \mathrm{N} 2$ & 4 & $2.892(2)$ & 177.9 & I & 18 \\
\hline & $\mathrm{I} 3 \cdots \mathrm{N} 3$ & 2 & $2.826(2)$ & 169.0 & I & 20 \\
\hline \multirow[t]{2}{*}{$(1,4-d i-I-t F b) \cdot(2,4-b p e)$} & $\mathrm{I} 2 \cdots \mathrm{N} 1$ & 4 & $2.802(4)$ & 177.5 & I & 21 \\
\hline & $\mathrm{I} 1 \cdots \mathrm{N} 2$ & 2 & $2.884(3)$ & 175.6 & $\mathrm{I}$ & 18 \\
\hline
\end{tabular}

* prs $\equiv$ percent relative shortening $=\left\{1-d(\mathrm{~N} \cdots \mathrm{I}) /\left[r_{\mathrm{vdW}}(\mathrm{I})+r_{\mathrm{vdW}}(\mathrm{N})\right]\right\} \cdot 100$, where $r_{\mathrm{vdW}}(\mathrm{N})$ and $r_{\mathrm{vdW}}(\mathrm{I})$ are the van der Waals radii for nitrogen and iodine, respectively, with $r_{\mathrm{vdW}}(\mathrm{N})=1.55 \AA$ and $r_{\mathrm{vdW}}(\mathrm{I})=1.98 \AA$.

Table 4. Struc ural features of cocrystals.

\begin{tabular}{|c|c|c|c|}
\hline Cocrystal & Primary Assembly & Secondary Assembly & Photoreactivity \\
\hline$(1,2-d i-I-t F b) \cdot(2,4-b p e)(2104746)$ & infinite $1 \mathrm{D}$ tape based on $\mathrm{N} \cdots \mathrm{I}$ & infinite 2D corrugated layers & active \\
\hline $\begin{array}{l}\text { 2(1,2-di-I-tFb) } \cdot(r c t t-h t-2,4-t p c b) \\
(2114529)\end{array}$ & infinite $1 \mathrm{D}$ chain based on $\mathrm{N} \cdots \mathrm{I}$ & infinite sheets based on $\mathrm{C}-\mathrm{H} \cdots \mathrm{F}$ & - \\
\hline$(\mathbf{1}, 3-\mathrm{di}-\mathrm{I}-\mathrm{tFb}) \cdot(\mathbf{2 , 4 - b p e})(2104747)$ & $\begin{array}{l}\text { discrete, four-component assembly } \\
\text { based on N } \cdots \text { I }\end{array}$ & infinite sheets based on $\mathrm{C}-\mathrm{H} \cdots \mathrm{F}$ & active \\
\hline $\begin{array}{l}\text { 2(1,3-di-I-tFb) }(\text { rctt-hh-2,4-tpcb) } \\
(2114285)\end{array}$ & $\begin{array}{l}\text { discrete, six-component assembly } \\
\text { based on } \mathrm{N} \cdots \mathrm{I} \text { and } \mathrm{C}-\mathrm{H} \cdots \mathrm{F}\end{array}$ & 3D network based on Type II I $\cdots$ I & - \\
\hline$(1,4-d i-I-t F b) \cdot(2,4-b p e)(2104748)$ & $\begin{array}{l}\text { infinite zig-zag chains } \\
\text { based on N...I }\end{array}$ & $\begin{array}{l}\text { infinite columns based on } \\
\text { Type II I … }\end{array}$ & inert \\
\hline
\end{tabular}

The alkene $\mathrm{C}=\mathrm{C}$ bonds of $(\mathbf{1}, \mathbf{2}-\mathrm{di}-\mathrm{I}-\mathrm{tFb}) \cdot(\mathbf{2 , 4}$-bpe) are photoactive. UV-irradiation (broadband $\mathrm{Hg}$ lamp, $100 \mathrm{~h}$ ) of the cocrystal (1,2-di-I-tFb).(2,4-bpe) resulted in stereospecific, regiospecific, and quantitative photodimerization of $\mathbf{2 , 4}$-bpe to generate $\boldsymbol{h t}$-2,4-tpcb (Scheme 2, Table 4) [17]. The formation of the cyclobutane photoproduct was evidenced by the complete disappearance of the pair of olefinic doublets $\left(\delta_{\mathrm{H}}=7.65,7.59 \mathrm{ppm}\right)$ with concomitant emergence of a pair of cyclobutane resonances $\left(\delta_{\mathrm{H}}=4.87-4.82,4.79-4.74 \mathrm{ppm}\right)$ in the ${ }^{1} \mathrm{H}$ NMR spectrum (Figure $\mathrm{S} 1$ of the ESI).

\subsection{X-ray Crystal Structure of 2(1,2-di-I-tFb)·(ht-2,4-tpcb)}

A single-crystal $X$-ray structure determination confirmed the $h t$-regiochemistry of $h t-2,4-t p c b$ (Figure 2). The components of 2(1,2-di-I-tFb) $(\boldsymbol{h t}$-2,4-tpcb) crystallize in the triclinic space group $P \overline{1}$ (Table 1 ). The asymmetric unit consists of one full molecule of 1,2-di-I-tFb and one half-molecule of $\boldsymbol{h t}$-2,4-tpcb, with the cyclobutane located around a crystallographic center of inversion (Figure 2a). The 2-pyr rings of $\boldsymbol{h} \boldsymbol{h}$-2,4-tpcb adopt an anti-conformation (Figure $2 \mathrm{~b}$ ). The components assemble primarily via N...I X-bonds 
$(d(\mathrm{~N} 1 \cdots \mathrm{I} 1)=2.946(4) \AA ; d(\mathrm{~N} 2 \cdots \mathrm{I} 2)=3.022(4) \AA$, Table 3$)$ to form $1 \mathrm{D}$ assemblies that propagate along the crystallographic $c$-axis with 1,2-di-I-tFb bridging $\boldsymbol{h t}$-2,4-tpcb (Figure $2 \mathrm{~b}$, Table 4). Adjacent assemblies interact primarily via edge-to-edge $\mathrm{C}-\mathrm{H} \cdots \mathrm{F}$ forces $(d(\mathrm{H} 16 \cdots \mathrm{F} 1)$ $\sim 2.52 \AA$ ) to form 2D sheets (Figure 2c,d, Table 4).

a)

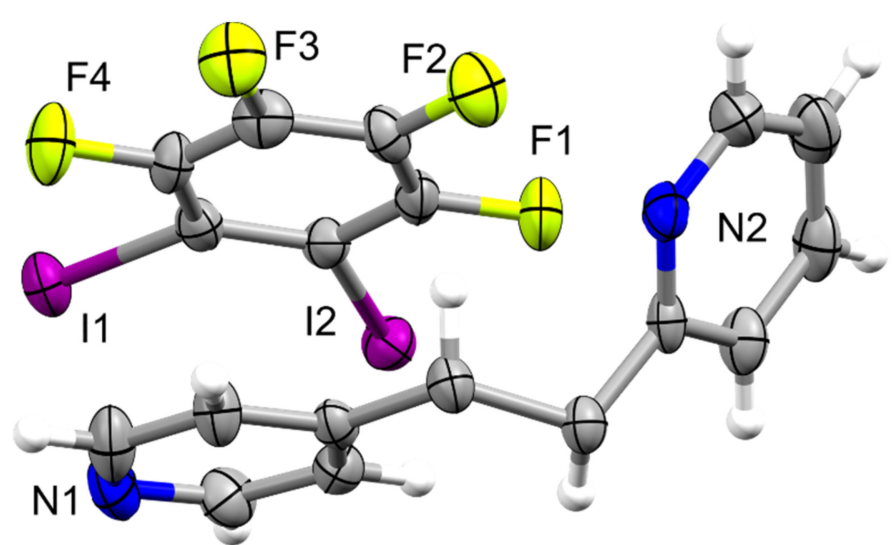

b)

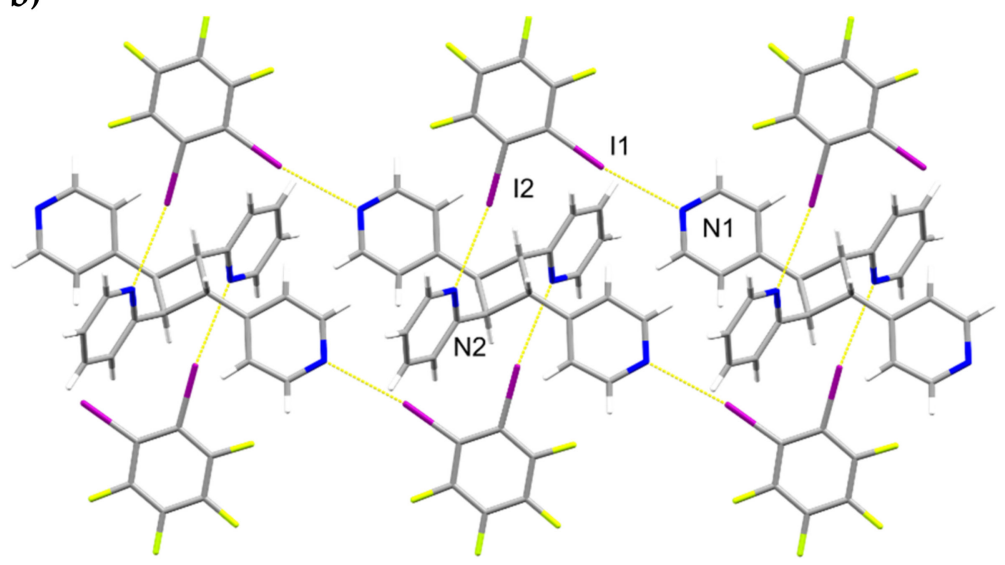

c)

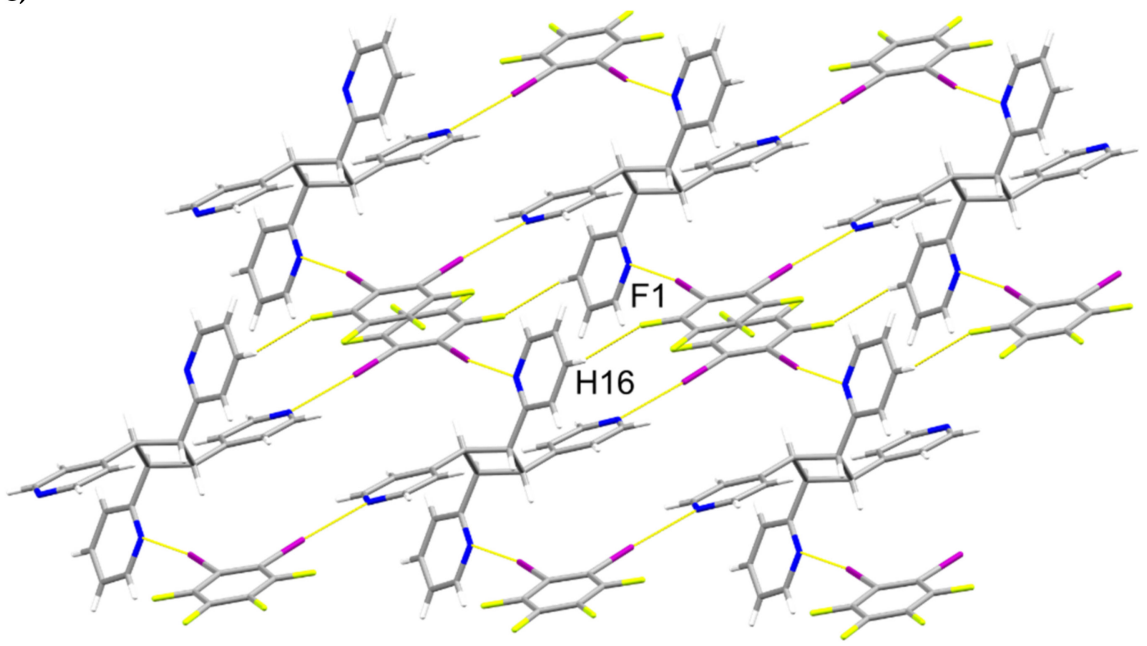

Figure 2. Perspectives of 2(1,2-di-I-tFb) ( $h$ t-2,4-tpcb): (a) asymmetric unit (anisotropic displacement ellipsoids at $50 \%$ probability); (b) $1 \mathrm{D}$ assemblies; and (c) sheets based on $\mathrm{C}-\mathrm{H} \cdots \mathrm{F}$ forces. 


\subsection{X-ray Crystal Structure of (1,3-di-I-tFb):(2,4-bpe)}

The components of (1,3-di-I-tFb) $\cdot(\mathbf{2}, \mathbf{4}-\mathbf{b p e})$ crystallize in the monoclinic space group $P 2_{1} / n$ (Figure 3, Table 5). The asymmetric unit consists of one full molecule each of $\mathbf{1 , 3}$ di-I-tFb and 2,4-bpe (Figure 3a). The alkene $\mathrm{C}=\mathrm{C}$ bond of 2,4-bpe lies disordered over two sites (occupancies: $0.75 / 0.25$ ). The pyr rings of 2,4-bpe lie approximately coplanar $\left(\phi \sim 3.9^{\circ}\right.$, Table 2$)$. The components assemble via a combination of $\mathrm{N} \cdots \mathrm{I}$ X-bonds $(d(\mathrm{~N} 1 \cdots \mathrm{I} 1)=2.795(4) \AA) ; d(\mathrm{~N} 2 \cdots \mathrm{I} 2)=2.926(4) \AA$, Table 3$)$ and offset, edge-to-edge C-H $\cdots \mathrm{F}$ forces $(d(\mathrm{H} 7 \mathrm{~A} \cdots \mathrm{I} 2) \sim 2.99 \AA)$ to form discrete, four-component rhomboids $\left(\theta_{1} \sim 62.6^{\circ}\right.$; $\theta_{2} \sim 117.4^{\circ} ; l_{1} \sim 14.3 \AA ; l_{2} \sim 7.8 \AA$ ) (Figure $3 \mathrm{~b}, \mathrm{c}$, Table 4 ). Adjacent assemblies interact primarily via edge-to-edge $\mathrm{C}-\mathrm{H} \cdots \mathrm{F}$ forces between an alkenyl $\mathrm{H}$-atom of 2,4-bpe and 1,3di-I-tFb $(d(\mathrm{H} 6 \mathrm{~A} \cdots \mathrm{F} 2) \sim 2.54 \AA$; $d(\mathrm{H} 11 \cdots \mathrm{F} 4) \sim 2.53 \AA)$ to form sheets (Figure 3d, Table 4). Adjacent sheets interact via offset, face-to-face $\pi$-stacks between the 2-pyr and 4-pyr rings of neighboring molecules of 2,4-bpe $\left(d\left(\mathrm{pyr}_{\mathrm{N} 1} \cdots \mathrm{pyr}_{\mathrm{N} 2}\right) \sim 5.10 \AA\right)$. Nearest-neighbor molecules of 2,4-bpe stack head-to-head $(h h)$ with alkene $C=C$ bonds separated by $4.22 \AA$ and with closest alkene $\mathrm{C}=\mathrm{C}$ bonds stacked in a combination of parallel and crisscrossed geometries (Figure 3d) [18,19].

The alkene $\mathrm{C}=\mathrm{C}$ bonds of $(\mathbf{1 , 3}-\mathbf{d i}-\mathrm{I}-\mathbf{t F b}) \cdot(\mathbf{2}, \mathbf{4}-\mathbf{b p e})$ are photoactive. When (1,3-di-I$\mathbf{t F b}) \cdot(\mathbf{2}, \mathbf{4}-\mathbf{b p e}$ ) was subjected to UV-irradiation (broadband Hg lamp, 80 h), 2,4'-bpe underwent a photodimerization to generate $\boldsymbol{h} \boldsymbol{h}$-2,4-tpcb stereospecifically, regiospecifically, and in quantitative conversion [20] (Scheme 2, Table 4). The formation of the photoproduct was evidenced by the complete disappearance of the pair of olefinic doublets $\left(\delta_{\mathrm{H}}=7.65,7.59\right.$ $\mathrm{ppm})$ with concomitant emergence of a pair of cyclobutane resonances $\left(\delta_{\mathrm{H}}=4.89,4.69 \mathrm{ppm}\right)$ in the ${ }^{1} \mathrm{H}$ NMR spectrum (Figure $\mathrm{S} 3$ of the ESI). The reactivity was presumably supported by the pedal-like motion of the disordered alkene $C=C$ bonds upon irradiation $[19,21-30]$.

a)

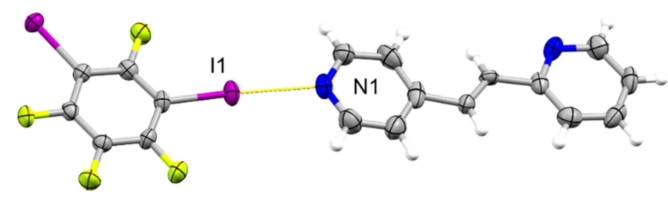

b)

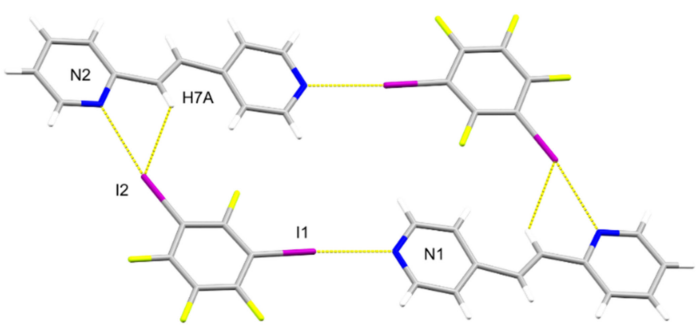

c)

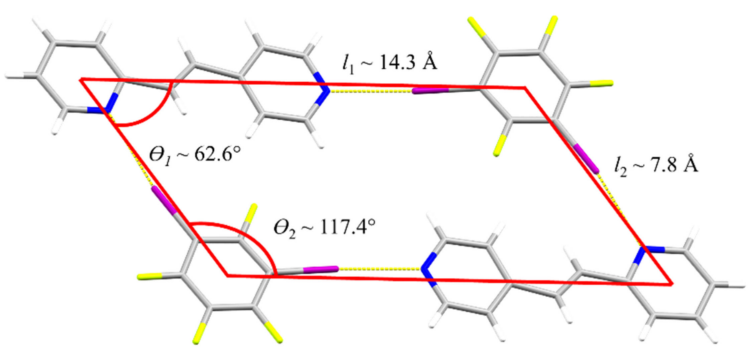

Figure 3. Cont. 
d)

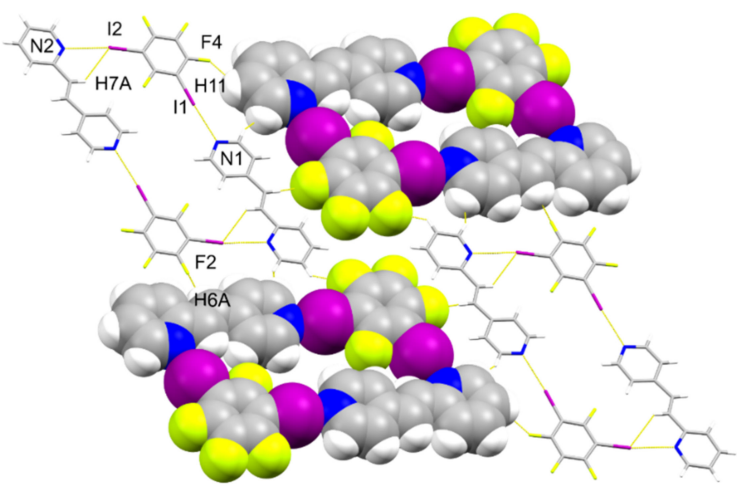

e)

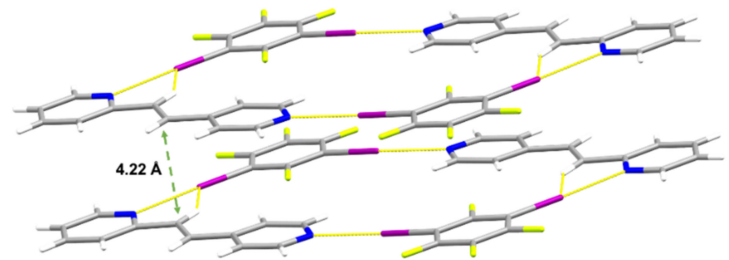

Figure 3. Perspectives of (1,3-di-I-tFb)·(2,4-bpe) (minor fraction of alkene disorder omitted for clarity): (a) asymmetric unit (anisotropic displacement ellipsoids at 50\% probability); (b) fourcomponent assembly; (c) rhomboidal repeat highlighted (C-H $\cdots$ I contacts omitted for clarity); (d) sheets with two assemblies shown as space filling; and (e) nearest-neighbor alkenes between adjacent sheets highlighting closest alkene separation (green dashed arrow).

\subsection{X-ray Crystal Structure of 2(1,3-di-I-tFb).(hh-2,4-tpcb)}

A single-crystal X-ray structure determination confirmed the $h h$-regiochemistry of $\boldsymbol{h} \boldsymbol{h}$-2,4-tpcb (Figure 4). The components of 2(1,3-di-I-tFb) $(\boldsymbol{h} \boldsymbol{h}-\mathbf{2 , 4 - t p c b})$ crystallize in the triclinic space group $P \overline{1}$ (Table 5). The asymmetric unit consists of one full molecule of $\boldsymbol{h} \boldsymbol{h}$-2,4-tpcb and two full molecules of $\mathbf{1 , 3}$-di-I-tFb (Figure 4a). The 2-pyr rings of $\boldsymbol{h} \boldsymbol{h}$ 2,4-tpcb adopt an anti-conformation. The components assemble primarily via N...I Xbonds $(d(\mathrm{~N} 1 \cdots \mathrm{I} 1)=2.826(2) \AA ; d(\mathrm{~N} 2 \cdots \mathrm{I} 2)=2.892(2) \AA ; d(\mathrm{~N} 3 \cdots \mathrm{I} 3)=2.826(2) \AA ;$ Table 3$)$ and secondary edge-to-edge $\mathrm{C}-\mathrm{H} \cdots \mathrm{F}$ forces $(d(\mathrm{H} 1 \cdots \mathrm{F} 8) \sim 2.55 \AA)$ to form discrete, six-component assemblies (Figure 4 b, Table 4). In contrast to 2(1,2-di-I-tFb) $\cdot(\boldsymbol{h t}$-2,4-tpcb), wherein all four pyr $\mathrm{N}$-atoms participate in $\mathrm{N} \cdots \mathrm{I}$ X-bonds, only three $\mathrm{N}$-atoms of 2(1,3-di-I-tFb) $\cdot(\boldsymbol{h} \boldsymbol{h}$-2,4tpcb) participate in N …I X-bonds (Figure $4 b$ ). Adjacent assemblies interact primarily via Type II [22] I $\cdots$ I X-bonds $(d(\mathrm{I} 2 \cdots \mathrm{I} 4)=3.6970(4) \AA)$ to form an extended X-bonded network (Figure 4c, Table 4).

The alkene $\mathrm{C}=\mathrm{C}$ bonds of $(\mathbf{1 , 3}-\mathrm{di}-\mathrm{I}-\mathbf{t F b}) \cdot(\mathbf{2}, \mathbf{4}-\mathbf{b p e})$ are photoactive. When (1,3-di-ItFb) $\cdot(\mathbf{2}, \mathbf{4}$-bpe) was subjected to UV-irradiation (broadband Hg lamp, 80 h), 2,4'-bpe underwent a photodimerization to generate $\boldsymbol{h} \boldsymbol{h}$-2,4-tpcb stereospecifically, regiospecifically, and in quantitative conversion [20] (Scheme 2, Table 4). The formation of the photoproduct was evidenced by the complete disappearance of the pair of olefinic doublets $\left(\delta_{\mathrm{H}}=7.65,7.59 \mathrm{ppm}\right)$ with concomitant emergence of a pair of cyclobutane resonances $\left(\delta_{\mathrm{H}}=4.89,4.69 \mathrm{ppm}\right)$ in the ${ }^{1} \mathrm{H}$ NMR spectrum (Figure S3 of the ESI). The reactivity was presumably supported by the pedal-like motion of the disordered alkene $\mathrm{C}=\mathrm{C}$ bonds upon irradiation $[19,21-30]$.

\subsection{X-ray Crystal Structure of 2(1,3-di-I-tFb).(hh-2,4-tpcb)}

A single-crystal X-ray structure determination confirmed the $h h$-regiochemistry of $\boldsymbol{h} \boldsymbol{h}$-2,4-tpcb (Figure 4). The components of 2(1,3-di-I-tFb) $(\boldsymbol{h} \boldsymbol{h}$-2,4-tpcb) crystallize in the triclinic space group $P \overline{1}$ (Table 5). The asymmetric unit consists of one full molecule of $\boldsymbol{h} \boldsymbol{h}$-2,4-tpcb and two full molecules of $\mathbf{1 , 3 - d i - I - t F b}$ (Figure 4a). The 2-pyr rings of $\boldsymbol{h} \boldsymbol{h}$ - 
2,4-tpcb adopt an anti-conformation. The components assemble primarily via N $\cdots I$ Xbonds $(d(\mathrm{~N} 1 \cdots \mathrm{I} 1)=2.826(2) \AA ; d(\mathrm{~N} 2 \cdots \mathrm{I} 2)=2.892(2) \AA ; d(\mathrm{~N} 3 \cdots \mathrm{I} 3)=2.826(2) \AA ;$ Table 3$)$ and secondary edge-to-edge C-H $\cdots$ F forces $(d(\mathrm{H} 1 \cdots \mathrm{F} 8) \sim 2.55 \AA)$ to form discrete, six-component assemblies (Figure 4b, Table 4). In contrast to 2(1,2-di-I-tFb) $(\boldsymbol{h t}$-2,4-tpcb), wherein all four pyr N-atoms participate in N...I X-bonds, only three $\mathrm{N}$-atoms of $2(\mathbf{1}, \mathbf{3}$-di-I-tFb) $(\boldsymbol{h} \boldsymbol{h}-\mathbf{2}, \mathbf{4}-$ tpcb) participate in N...I X-bonds (Figure 4b). Adjacent assemblies interact primarily via Type II [22] I …I X-bonds $(d(\mathrm{I} 2 \cdots \mathrm{I} 4)=3.6970(4) \AA)$ to form an extended X-bonded network (Figure 4c, Table 4).

Table 5. Crystallographic data and structure refinement statistics *.

\begin{tabular}{|c|c|c|c|}
\hline Cocrystal & $(1,3-d i-I-t F b) \cdot(2,4-b p e)$ & 2(1,3-di-I-tFb) $\cdot(h h-2,4-t p c b)$ & $(1,4-d i-I-t F b) \cdot(2,4-b p e)$ \\
\hline CCDC deposition number & 2104747 & 2114285 & 2104748 \\
\hline Empirical formula & $\mathrm{C}_{18} \mathrm{H}_{10} \mathrm{~F}_{4} \mathrm{I}_{2} \mathrm{~N}_{2}$ & $\mathrm{C}_{36} \mathrm{H}_{20} \mathrm{~F}_{8} \mathrm{I}_{4} \mathrm{~N}_{4}$ & $\mathrm{C}_{18} \mathrm{H}_{10} \mathrm{~F}_{4} \mathrm{I}_{2} \mathrm{~N}_{2}$ \\
\hline Formula weight $/ \mathrm{g} \cdot \mathrm{mol}^{-1}$ & 584.08 & 1168.16 & 584.08 \\
\hline Temperature/K & $150(2)$ & $150(2)$ & $150(2)$ \\
\hline Crystal system & Monoclinic & Triclinic & Monoclinic \\
\hline Space group & $P 2_{1} / n$ & $P-1$ & $P 2_{1} / c$ \\
\hline$a / \AA$ & $4.2177(4)$ & $8.1884(6)$ & $17.7168(18)$ \\
\hline$b / \AA$ & $27.254(3)$ & $14.2749(14)$ & $5.2208(5)$ \\
\hline$c / \AA$ & 16.1797(16) & 16.3737(16) & $20.159(2)$ \\
\hline$\alpha /^{\circ}$ & 90 & $82.111(5)$ & 90 \\
\hline$\beta /{ }^{\circ}$ & $90.940(5)$ & $87.336(5)$ & $103.519(5)$ \\
\hline$\gamma /{ }^{\circ}$ & 90 & $73.759(5)$ & 90 \\
\hline Volume $/ \AA^{3}$ & $1859.6(3)$ & $1820.1(3)$ & $1813.0(3)$ \\
\hline Z & 4 & 2 & 4 \\
\hline$\rho_{\text {calc }} / \mathrm{g} \cdot \mathrm{cm}^{-3}$ & 2.09 & 2.13 & 2.14 \\
\hline$\mu / \mathrm{mm}^{-1}$ & 3.424 & 3.498 & 3.512 \\
\hline$F(000)$ & 1096 & 1096 & 1096 \\
\hline Crystal size $/ \mathrm{mm}^{3}$ & $0.15 \times 0.15 \times 0.05$ & $0.07 \times 0.06 \times 0.05$ & $0.27 \times 0.09 \times 0.02$ \\
\hline Radiation & $\operatorname{MoK} \alpha(\lambda=0.71073)$ & $\operatorname{MoK} \alpha(\lambda=0.71073)$ & $\operatorname{MoK} \alpha(\lambda=0.71073)$ \\
\hline $2 \Theta$ range for data collection $/{ }^{\circ}$ & 5.036 to 50.244 & 4.152 to 50.246 & 4.156 to 50.246 \\
\hline Index ranges & $\begin{array}{c}-5 \leq \mathrm{h} \leq 5,-32 \leq \mathrm{k} \leq 32 \\
-18<1<19\end{array}$ & $\begin{array}{c}-9 \leq \mathrm{h} \leq 9,-17 \leq \mathrm{k} \leq 17 \\
-18<1<19\end{array}$ & $\begin{array}{c}-21 \leq \mathrm{h} \leq 21,-24 \leq \mathrm{k} \leq 24, \\
-23<1<23\end{array}$ \\
\hline Reflections collected & 38879 & 34954 & $4 \overline{64} 5 \overline{4}$ \\
\hline Independent reflections & $\begin{array}{c}3283\left[R_{\text {int }}=0.0379,\right. \\
\left.R_{\text {in }}=0.0213\right]\end{array}$ & $6475\left[R_{\text {int }}=0.0264\right.$ & $3233\left[R_{\text {int }}=0.0362\right.$ \\
\hline Data/restraints/parameters & $\begin{array}{l}\text { Nigma }-0.0210] \\
3234 / 18 / 253\end{array}$ & $\begin{array}{c}\left.\Lambda_{\text {sigma }}-0.0104\right] \\
6475 / 0 / 469\end{array}$ & Nigma -0.0135 \\
\hline Goodness-of-fit on $F^{2}$ & 1.082 & 1.033 & 1.049 \\
\hline Final $R$ indices $[I \geq 2 \sigma(I)]$ & $R_{1}=0.0299$ & $R_{1}=0.0174$ & $R_{1}=0.0248$ \\
\hline & $w R_{2}=0.0802$ & $w R_{2}=0.0365$ & $w R_{2}=0.0538$ \\
\hline$R$ indices (all data) & $\begin{array}{c}R_{1}=0.0306 \\
w R_{2}=0.0807\end{array}$ & $\begin{array}{c}R_{1}=0.0222 \\
w R_{2}=0.0387\end{array}$ & $\begin{array}{c}R_{1}=0.0271 \\
w R_{2}=0.0551\end{array}$ \\
\hline $\begin{array}{c}\text { Largest diff. } \\
\text { peak/hole } / \mathrm{e} \cdot \AA^{-3}\end{array}$ & $0.79 /-0.63$ & $1.20 /-1.00$ & $0.71 /-0.60$ \\
\hline
\end{tabular}

${ }^{*} R_{1}=\sum|| F_{\mathrm{o}}|-| F_{\mathrm{c}}|| / \sum\left|F_{\mathrm{o}}\right|, w R_{2}=\left[\sum w\left(F_{\mathrm{o}}^{2}-F_{\mathrm{c}}^{2}\right)^{2}\right] / \sum\left[w\left(F_{\mathrm{o}}^{2}\right)^{2}\right]^{1 / 2}$. Goodness-of-fit on $F^{2}=\left[\sum w\left(\left|F_{\mathrm{o}}\right|-\left|F_{\mathrm{c}}\right|\right)^{2}\right.$ $/\left(N_{\text {obs }}-N_{\text {parameter }}\right)^{1 / 2}$.

\subsection{Structural Considerations}

The unsymmetrical nature of 2,4-bpe provides two different pyr N-atoms (i.e., 2-pyr versus 4-pyr) to participate in X-bonding. We note that in virtually all cases, the $\mathrm{N} \cdots \mathrm{I}$ $\mathrm{X}$-bond lengths involving I-atoms of the X-bond donors $\mathbf{1 , n - d i - I - t F b}$ to $\mathrm{N}$-atoms of the X-bond acceptors 2,4-bpe, $\boldsymbol{h t}$-2,4-tpcb, and $\boldsymbol{h} \boldsymbol{h}$-2,4-tpcb are shorter for 4-pyr versus 2-pyr (Table 3). The average percent relative shortening (prs) values for N...I X-bonds to 2-pyr versus 4-pyr $\mathrm{N}$ atoms were $15.7 \%$ and $19.5 \%$, respectively (Table 3 ). Given that $\mathrm{p} K_{\mathrm{a}}$ values for similar 4-pyr and 2-pyr analogs are comparable [31], we attribute the observation to greater steric crowding between the lone pair on the $\mathrm{N}$-atom of 2-pyr versus 4-pyr rings. Crowding would presumably preclude maximal orbital overlap (i.e., strongest X-bond formation) between the $\mathrm{N}$-atom lone pair and the $\sigma$-hole of the relatively large I-atoms relative to an appreciably less congested 4-pyr $\mathrm{N}$-atom. 
a)

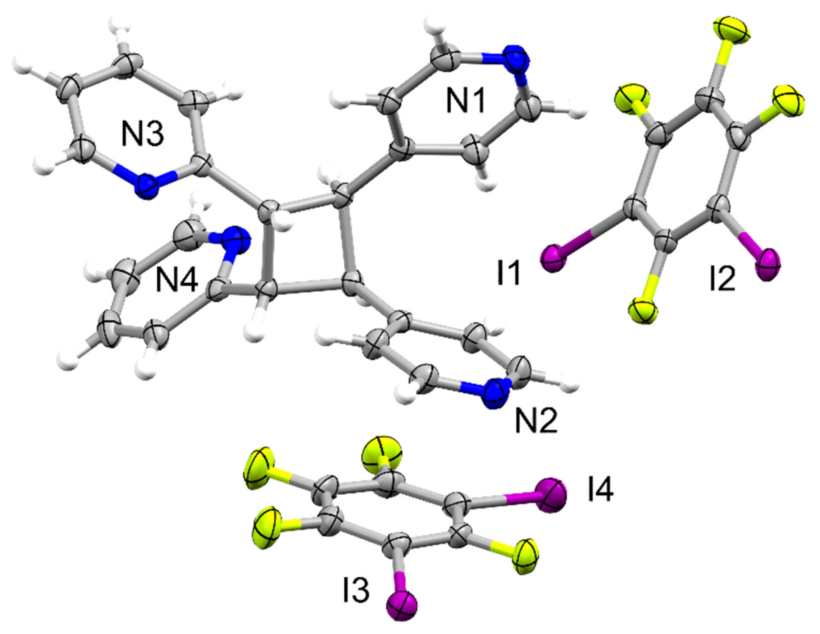

b)

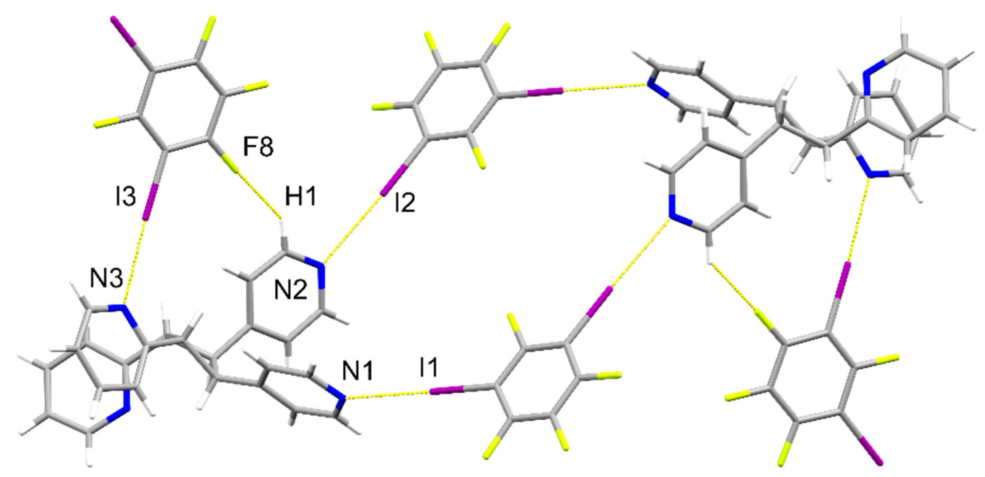

c)
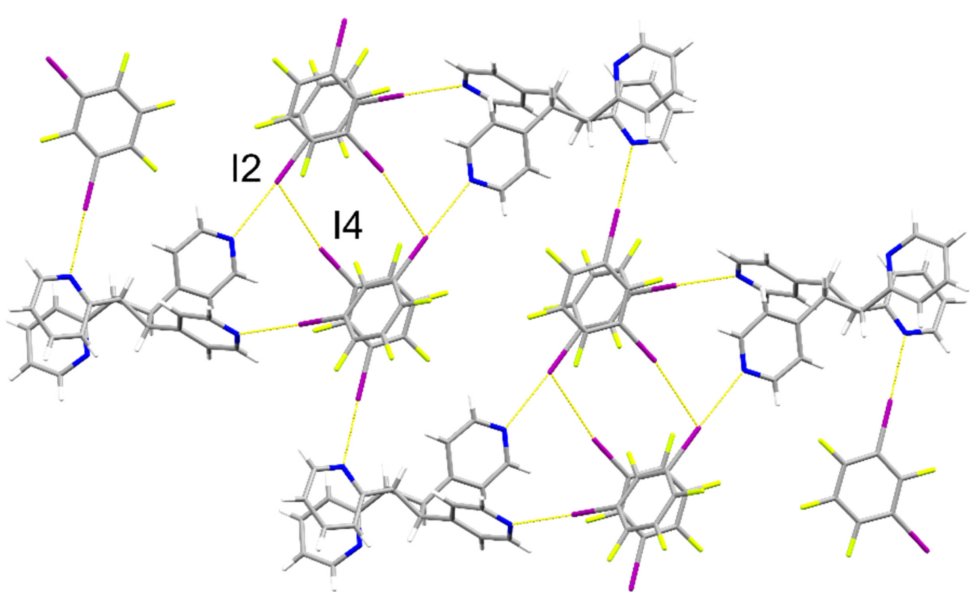

Figure 4. Perspectives of 2(1,3-di-I-tFb) ( $\boldsymbol{h} \boldsymbol{h}-\mathbf{2}, \mathbf{4}-\mathbf{t p c b})$ : (a) asymmetric unit (thermal ellipsoids shown at $50 \%$ probability); (b) discrete, six-component assembly; and (c) adjacent assemblies illustrating Type II I ...I X-bonds. 
<smiles>Cc1c(C)c(C)c(O)c(O)c1C</smiles>

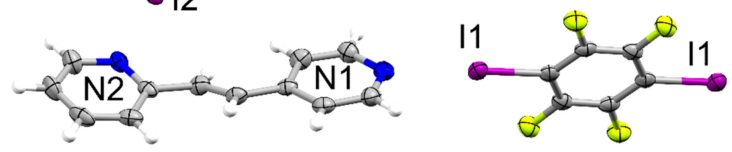

b)

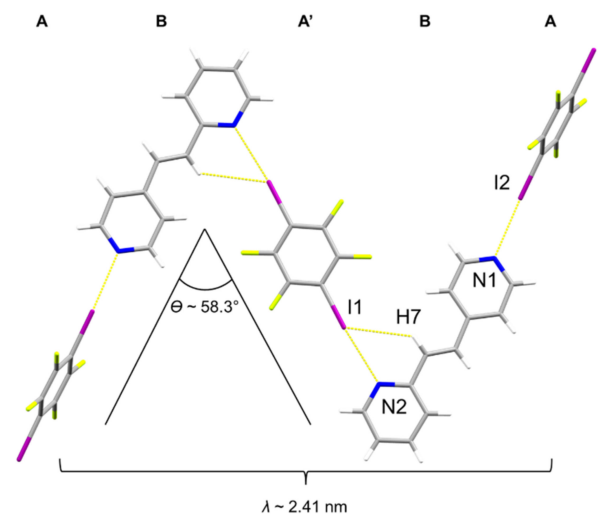

c)

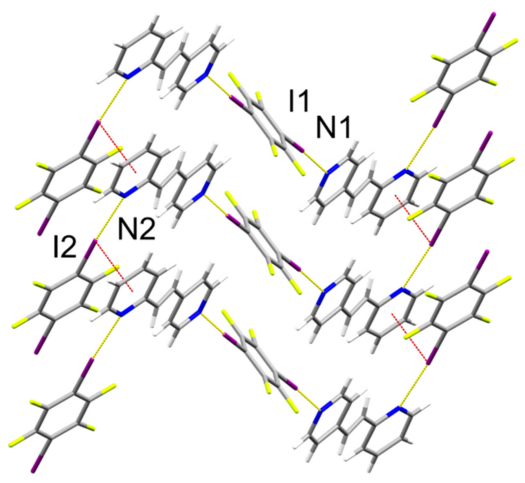

d)

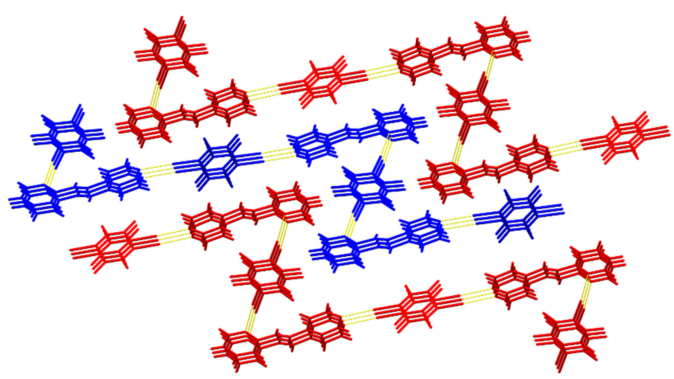

Figure 5. Perspectives of (1,4-di-I-tFb)·(2,4-bpe): (a) ORTEP (thermal ellipsoids shown at 50\% probability; view along $b$ ); (b) zig-zag chains illustrating ABA'B repeat; (c) columns highlighting

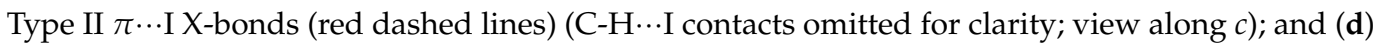
herringbone packing of columns.

\section{Materials and Methods}

\subsection{General Experimental}

All reagents and solvents (synthesis grade) were purchased from commercial sources and used as received unless otherwise stated. 1,2-diiodotetrafluorobenzene (1,2-di-I-tFb; 
99\%), trans-1-(2-pyridyl)-2-(4-pyridyl)ethylene (2,4-bpe; 97\%), and 1,4-diiodotetrafluorobenzene (1,4-di-I-tFb, 98\%) were purchased from Aldrich ${ }^{\odot}$. 1,3-diiodotetrafluorobenzene (1,3-diI-tFb; $97 \%$ ) was purchased from Apollo Scientific ${ }^{\circ}$ (Bredbury, UK). Chloroform $\left(\mathrm{CHCl}_{3}\right.$; certified ACS grade, $\geq 99.8 \%$, approximately $0.75 \% \mathrm{EtOH}$ as preservative) was purchased from Fisher $\mathrm{Chemical}^{\odot}$ (Hampton, NH, USA). All cocrystal syntheses were conducted in screw-cap glass scintillation vials. For cocrystal syntheses, "thermal dissolution" refers to the process of: (1) combining both cocrystal components in the same screw-cap glass vial; (2) adding solvent portion-wise while maintaining a saturated mixture at rt; and (3) tightly capping the vial and heating the mixture on a hotplate until all solids dissolve to afford a homogeneous solution in the minimum necessary volume of solvent. Compositions of all single crystals were shown to be representative of the bulk material by matching experimental pXRD patterns with those simulated from scXRD data. Photoreactions were conducted in an $\mathrm{ACE}^{\circledR}$ photo cabinet equipped with a water-cooled $\mathrm{ACE}^{\circledR}$ quartz, $450 \mathrm{~W}$, broadband $(\lambda=1367.3-222.4 \mathrm{~nm}$ ), medium pressure, Hg-vapor lamp (of the total energy emitted by the broadband lamp, approximately $40-48 \%$ is in the ultraviolet portion of the spectrum, $40-43 \%$ in the visible, and the balance in the infrared). Photoreactions were conducted by: (1) grinding single crystals of the cocrystal to a fine powder with an agate mortar and pestle; (2) smearing the powder between two UV-transparent Pyrex ${ }^{\circledR}$ plates to create the thinnest layer possible; and (3) irradiating the powder in $10 \mathrm{~h}$ intervals, taking care to ensure uniform irradiation. Uniform irradiation of the powdered cocrystals was accomplished by: (1) occasionally (between every other irradiation interval) scraping (razor blade) the irradiated powder from both plates of the plate assembly; (2) combining the powder from both plates; (3) homogenizing the combined, bulk powder via thorough grinding (agate mortar and pestle); and (4) redistributing the homogenized powder between both plates. The plate assembly was also flipped between irradiation intervals to ensure equal irradiation of both faces of the plate assembly.

\subsection{Synthetic Procedures}

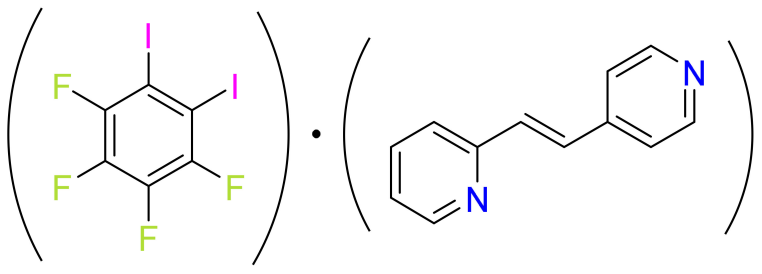

$(1,2-d i-I-t F b) \cdot(2,4-b p e)$

$(\mathbf{1 , 2}$-di-I-tFb) $\cdot(2,4-b p e)$. Cocrystals of (1,2-di-I-tFb).(2,4-bpe) were obtained by thermal dissolution of 2,4-bpe $(192.9 \mathrm{mg}, 1.03 \mathrm{mmol})$ and 1,2-di-I-tFb $(418.7 \mathrm{mg}, 1.03 \mathrm{mmol}$, 1.0 equiv) in $\mathrm{CHCl}_{3}(7.0 \mathrm{~mL})$. Upon cooling to rt, single crystals of (1,2-di-I-tFb) (2,4-bpe)colorless laths, suitable for scXRD—formed within $15 \mathrm{~d}$.

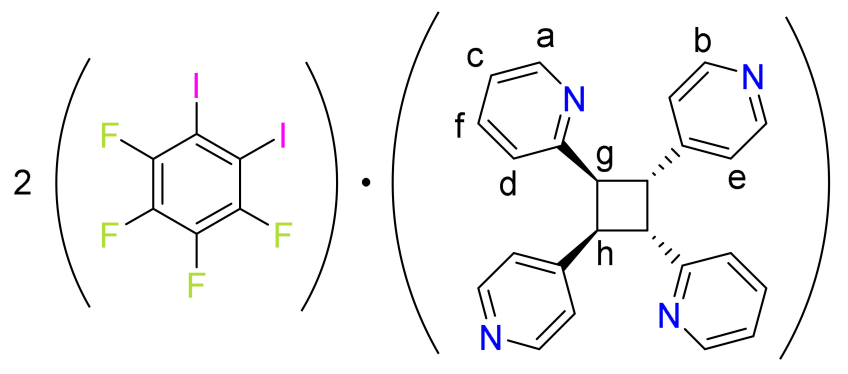

2(1,2-di-I-tFb) $\cdot($ ht-2,4-tpcb)

2(1,2-di-I-tFb) (ht-2,4-tpcb). Single crystals of (1,2-di-I-tFb) (2,4-bpe) were ground to a fine powder using an agate mortar and pestle and smeared between two Pyrex ${ }^{\circledR}$ plates. 
The plate assembly was placed in an $\mathrm{ACE}^{\circledR}$ photo cabinet. After $100 \mathrm{~h},{ }^{1} \mathrm{H}$ NMR assay revealed quantitative, stereospecific, and regiospecific conversion to $2(\mathbf{1}, \mathbf{2}-\mathbf{d i}-\mathrm{I}-\mathbf{t F b}) \cdot(\boldsymbol{h t} \mathbf{t} \mathbf{2 , 4} \mathbf{-}$ $\mathbf{t p c b})$. The product powder was scraped from the plates, dissolved in the minimum volume of boiling $\mathrm{CHCl}_{3}$, and allowed to slowly cool to rt: single crystals of 2(1,2-di-I-tFb) $(\boldsymbol{h t}$ - 2,4tpcb) - colorless, irregular prisms, suitable for scXRD—formed within $6 \mathrm{~d}$. Analytical data: ${ }^{1}$ H NMR (400 MHz, DMSO- $\left.d_{6}\right): \delta 8.40\left(\mathrm{dd}, J=4.80 .8 \mathrm{~Hz}, 2 \mathrm{H}_{\mathrm{a}}\right), 8.27(\mathrm{dd}, J=4.6,1.4 \mathrm{~Hz}$, $\left.4 \mathrm{H}_{\mathrm{b}}\right), 7.55\left(\mathrm{app} \mathrm{td}, J=7.6,1.8 \mathrm{~Hz}, 2 \mathrm{H}_{\mathrm{c}}\right), 7.19\left(\mathrm{~d}, J=7.8 \mathrm{~Hz}, 2 \mathrm{H}_{\mathrm{d}}\right), 7.16\left(\mathrm{~d}, J=6.0 \mathrm{~Hz}, 4 \mathrm{H}_{\mathrm{e}}\right)$, $7.06\left(\mathrm{ddd}, J=7.5,4.9,0.9 \mathrm{~Hz}, 2 \mathrm{H}_{\mathrm{f}}\right), 4.87-4.82\left(\mathrm{~m}, 2 \mathrm{H}_{\mathrm{g}}\right), 4.79-4.74\left(\mathrm{~m}, 2 \mathrm{H}_{\mathrm{h}}\right)$. Spectral data were consistent with those previously reported [17] for the same compound.

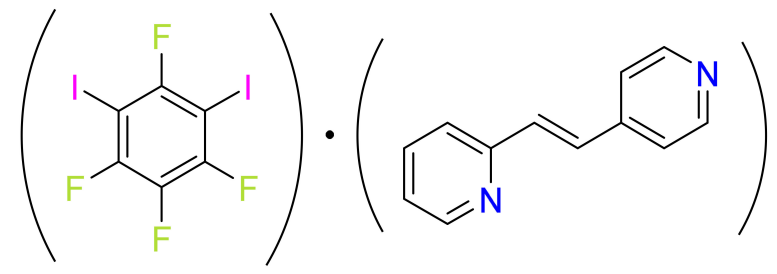

$(1,3-d i-I-t F b) \cdot(2,4-b p e)$

(1,3-di-I-tFb) (2,4-bpe). Cocrystals of (1,3-di-I-tFb) $\cdot(2,4-b p e)$ were obtained by thermal dissolution of 2,4-bpe (191.1 mg, $1.02 \mathrm{mmol})$ and 1,3-di-I-tFb $(430.5 \mathrm{mg}, 1.02 \mathrm{mmol}$, 1.0 equiv) in $\mathrm{CHCl}_{3}$ (7.0 mL). Upon cooling to rt, single crystals of (1,3-di-I-tFb).(2,4-bpe) colorless plates, suitable for scXRD—formed within $15 \mathrm{~d}$.

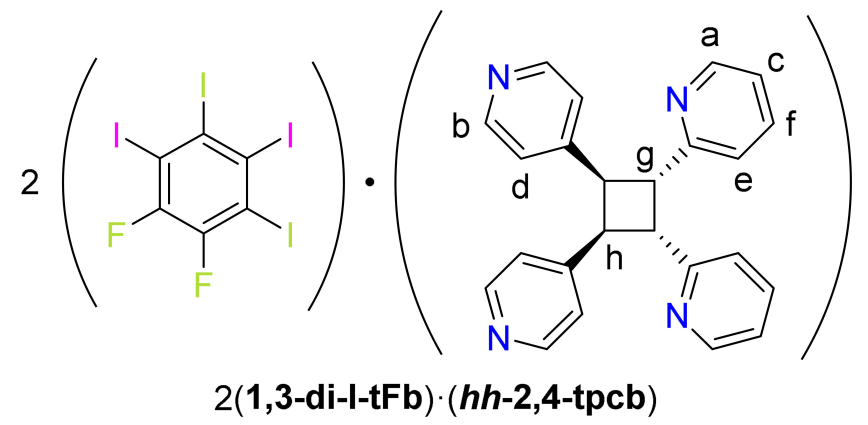

2(1,3-di-I-tFb) $(\boldsymbol{h} h$-2,4-tpcb). Single crystals of $(\mathbf{1}, 3-\mathrm{di}-\mathrm{I}-\mathrm{tFb}) \cdot(\mathbf{2 , 4}$-bpe) were ground to a fine powder using an agate mortar and pestle and smeared between two Pyrex ${ }^{\circledR}$ plates. The plate assembly was placed in an $A C E^{\circledR}$ photo cabinet. After $80 \mathrm{~h},{ }^{1} \mathrm{H}$ NMR assay revealed quantitative, stereospecific, and regiospecific conversion to 2(1,3-di-I-tFb).(hh2,4-tpcb). The product powder was scraped from the plates, dissolved in the minimum volume of boiling $\mathrm{CHCl}_{3}$, and allowed to slowly cool to rt: single crystals of 2(1,3-di-ItFb).(hh-2,4-tpcb)—colorless prisms, suitable for scXRD—formed within $6 \mathrm{~d}$. Note: When preparing a sample of these crystals for pXRD assay (dry-grinding with an agate mortar and pestle), the solid initially assumed a moist, paste-like consistency, but eventually dried upon sitting exposed to air for several hours at rt. Analytical data: ${ }^{1} \mathbf{H}$ NMR $(400 \mathrm{MHz}$, DMSO- $\left.d_{6}\right): \delta 8.33\left(\mathrm{ddd}, J=4.8,1.7,0.9 \mathrm{~Hz}, 2 \mathrm{H}_{\mathrm{a}}\right), 8.31\left(\mathrm{dd}, J=4.5,1.5 \mathrm{~Hz}, 4 \mathrm{H}_{\mathrm{b}}\right), 7.50($ app $\left.\mathrm{td}, J=7.7,1.8 \mathrm{~Hz}, 2 \mathrm{H}_{\mathrm{c}}\right), 7.21\left(\mathrm{dd}, J=4.5,1.6 \mathrm{~Hz}, 4 \mathrm{H}_{\mathrm{d}}\right), 7.12\left(\mathrm{~d}, J=7.8 \mathrm{~Hz}, 2 \mathrm{H}_{\mathrm{e}}\right), 7.02(\mathrm{ddd}$, $\left.J=7.5,4.9,1.0 \mathrm{~Hz}, 2 \mathrm{H}_{\mathrm{f}}\right), 4.89\left(\mathrm{~d}, J=6.4 \mathrm{~Hz}, 2 \mathrm{H}_{\mathrm{g}}\right), 4.69\left(\mathrm{~d}, J=6.3 \mathrm{~Hz}, 2 \mathrm{H}_{\mathrm{h}}\right)$. Spectral data were consistent with those previously reported [20] for the same compound. 


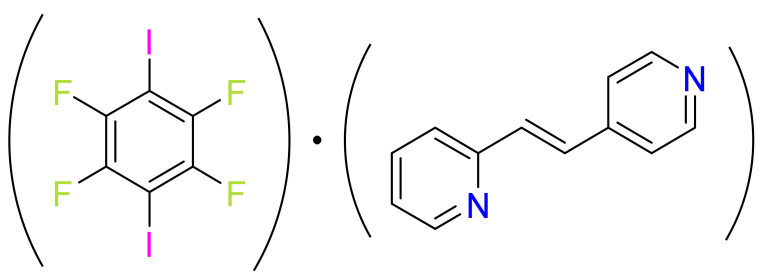

$(1,4-d i-I-t F b) \cdot(2,4-b p e)$

$(\mathbf{1}, 4$-di-I-tFb) $\cdot(2,4-b p e)$. Cocrystals of $(\mathbf{1 , 4 - d i - I - t F b ) \cdot ( 2 , 4 - b p e ) ~ w e r e ~ o b t a i n e d ~ b y ~ t h e r - ~}$ mal dissolution of 2,4-bpe $(194.0 \mathrm{mg}, 1.03 \mathrm{mmol})$ and 1,4-di-I-tFb (428.8 $\mathrm{mg}, 1.05 \mathrm{mmol}$, 1.0 equiv) in $\mathrm{CHCl}_{3}(7.0 \mathrm{~mL})$. Upon cooling to rt, single crystals of $(\mathbf{1}, \mathbf{4}$-di-I-tFb).(2,4-bpe)colorless blades, suitable for scXRD_formed within $11 \mathrm{~d}$.

\subsection{H NMR Spectroscopy}

Proton nuclear magnetic resonance $\left({ }^{1} \mathrm{H}\right.$ NMR) spectra were recorded at room temperature on a Bruker ${ }^{\circledR}$ AVANCE NEO-400 spectrometer (Bruker Corp., Billerica, MA, USA) operating at $400 \mathrm{MHz}$ using a liquid- $\mathrm{N}_{2}$-cooled double-resonance broadband Prodigy ${ }^{\mathrm{TM}}$ cryoprobe. ${ }^{1} \mathrm{H}$ NMR data are reported as follows: chemical shift $(\delta, \mathrm{ppm})$, multiplicity $(\mathrm{d}=$ doublet, $\mathrm{dd}=$ doublet of doublets, $\mathrm{ddd}=$ doublet of doublet of doublets, app $\mathrm{td}=$ apparent triplet of doublets, $\mathrm{m}=$ multiplet $)$, coupling constant $(\mathrm{s})(\mathrm{J}, \mathrm{Hz})$, and integration. Chemical shift values were calibrated relative to residual solvent resonance (central peak of DMSO: $\delta_{\mathrm{H}}=2.50 \mathrm{ppm}$ ) as the internal standard. All ${ }^{1} \mathrm{H}$ NMR data were collected and plotted within the Bruker ${ }^{\circledR}$ TopSpin ${ }^{\mathrm{TM}}$ v3.6.1 software suite.

\subsection{Powder X-ray Diffraction ( $p X R D)$}

Powder X-ray diffraction ( $\mathrm{pXRD}$ ) data were collected at room temperature on a Bruker ${ }^{\circledR}$ D8 Advance X-ray diffractometer (Bruker Corp., Billerica, MA, USA) on samples mounted on glass slides. Each sample was finely ground using an agate mortar and pestle prior to mounting. Instrument parameters: radiation wavelength, $\mathrm{CuK} \alpha(\lambda=1.5418 \AA)$; scan type, coupled TwoTheta/Theta; scan mode, continuous PSD fast; scan range, $5-40^{\circ}$ two-theta; step size, $0.02^{\circ}$; voltage, $40 \mathrm{kV}$; current, $30 \mathrm{~mA}$. Background subtractions were applied to all experimentally collected data within the Bruker ${ }^{\circledR}$ DIFFRAC.EVA v3.1 software suite. All data were plotted in the Microsoft ${ }^{\circledR}$ Excel 2016 software suite. Simulated pXRD patterns were calculated from scXRD data within the CCDC Mercury [32] software suite.

\subsection{Single-Crystal X-ray Diffraction (scXRD)}

Single-crystal X-ray diffraction data were collected on a Bruker ${ }^{\circledR}$ D8 VENTURE ${ }^{\circledR}$ (DUO) CCD diffractometer (Bruker Corp., Billerica, MA, USA) equipped with a Bruker ${ }^{\circledR}$ PHOTON III ${ }^{\circledR}$ photon counting detector and an Oxford Cryostream ${ }^{\circledR} 800$ series cold $\mathrm{N}_{2}$ gas stream cooling system (Oxford Cryosystems, Oxford, UK). Data were collected at a low temperature (150(2) K) using graphite-monochromated MoK $\alpha$ radiation $(\lambda=0.71073 \AA)$. Crystals were mounted in Paratone ${ }^{\circledR}$ oil on a MiTeGen ${ }^{\circledR}$ magnetic mount. Data collection strategies for ensuring maximum data redundancy and completeness were calculated using the Bruker ${ }^{\circledR}$ Apex II ${ }^{\mathrm{TM}}$ software suite. Data collection, initial indexing, frame integration, Lorentz-polarization corrections and final cell parameter calculations were likewise accomplished using the Apex II software suite. Multi-scan absorption corrections were performed using SADABS [33]. Structure solution and refinement were accomplished using SHELXT [34] and SHELXL [35], respectively, within the Olex2 [36] v1.2 graphical user interface. Space groups were unambiguously verified using the PLATON ${ }^{\odot}$ [37] executable. All non-hydrogen atoms were refined anisotropically. All hydrogen atoms were attached via a riding model at calculated positions using suitable HFIX commands. The occupancies of the major and minor positions for the disordered alkene $\mathrm{C}=\mathrm{C}$ core within (1,3-di-I-tFb)·(2,4-bpe) converged to their respective ratios after each was identified in the 
difference map and freely refined. Figures of all structures were rendered in the CCDC Mercury [32] software suite.

\section{Conclusions}

$\mathrm{N}$... I X-bonds have been used to support topochemical [2+2] photodimerizations of an unsymmetrical alkene to generate either of two regioisomeric cyclobutane photoproducts in the organic solid state. The transformations proceeded stereospecifically, regiospecifically, and quantitatively to generate $\boldsymbol{h t}$ - or $\boldsymbol{h} \boldsymbol{h}-\mathbf{2 ,} \mathbf{4}$-tpcb. Our contribution, thus, can be considered to afford à la carte access to either regioisomer. The formation of each product is achieved from the same alkene substrate, 2,4'-bpe, using commercially available X-bond donor cocrystal formers. Our future efforts will aim to expand the scope of the supramolecular methodology described herein to other unsymmetrical alkenes to afford access to additional unsymmetrical cyclobutane photoproducts.

Supplementary Materials: The following are available online. Figure S1: Stacked ${ }^{1} \mathrm{H}$ NMR spectra

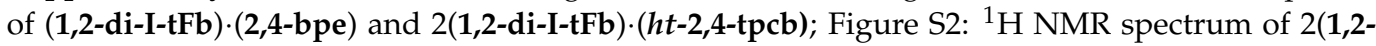

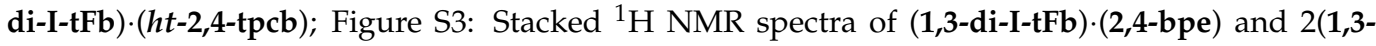
di-I-tFb).(hh-2,4-tpcb); Figure S4: ${ }^{1} \mathrm{H}$ NMR spectrum of 2(1,3-di-I-tFb).(hh-2,4-tpcb); Figure S5: pXRD pattern of (1,2-di-I-tFb) (2,4-bpe); Figure S6: pXRD pattern of 2(1,2-di-I-tFb) $(h t-2,4-t p c b)$ (as-synthesized); Figure S7: pXRD pattern of 2(1,2-di-I-tFb).(ht-2,4-tpcb); Figure S8: pXRD pattern of (1,3-di-I-tFb) $\cdot(2,4-b p e)$; Figure S9: pXRD pattern of 2(1,3-di-I-tFb) $(h h-2,4-t p c b)$; Figure S10: pXRD pattern of (1,4-di-I-tFb) $(2,4-b p e)$.

Author Contributions: Conceptualization: J.Q. and L.R.M.; methodology: J.Q.; formal analysis: J.Q., E.W.R. and L.R.M.; investigation: J.Q. and L.R.M.; resources: L.R.M.; writing-original draft preparation: J.Q., E.W.R. and L.R.M.; writing-review and editing: J.Q., E.W.R. and L.R.M.; supervision: L.R.M.; funding acquisition: L.R.M. All authors have read and agreed to the published version of the manuscript.

Funding: This research was funded by the National Science Foundation, grant numbers LRM DMR1708673 and CHE-1828117.

Institutional Review Board Statement: Not applicable.

Informed Consent Statement: Not applicable.

Data Availability Statement: The data presented in this study are available in the article, Cambridge Structural Database (CSD), or the Supplementary Materials.

Acknowledgments: We thank Dale Swenson for discussions on X-ray crystallography.

Conflicts of Interest: The authors declare no conflict of interest. The funders had no role in the design of the study; in the collection, analyses, or interpretation of data; in the writing of the manuscript; or in the decision to publish the results.

Sample Availability: Samples of the compounds (1,2-di-I-tFb).(2,4-bpe), 2(1,2-di-I-tFb) ( $h t-2,4-$ tpcb), (1,3-di-I-tFb)·(2,4-bpe), 2(1,3-di-I-tFb) $(h h-2,4-t p c b), h t-2,4-t p c b$, and $h h$-2,4-tpcb are available from the authors upon request. are available from the authors.

\section{References}

1. Dunning, T.J.; Unruh, D.K.; Bosch, E.; Groeneman, R.H. Controlling Topology within Halogen-Bonded Networks by Varying the Regiochemistry of the Cyclobutane-Based Nodes. Molecules 2021, 26, 3152. [CrossRef] [PubMed]

2. Sinnwell, M.A.; Santana, C.L.; Bosch, E.; MacGillivray, L.R.; Groeneman, R.H. Application of a tetrapyrimidyl cyclobutane synthesized in the organic solid state: A halogen-bonded supramolecular ladder. CrystEngComm 2020, 22, 6780-6782. [CrossRef]

3. Oburn, S.M.; Sinnwell, M.A.; Ericson, D.P.; Reinheimer, E.W.; Proserpio, D.M.; Groeneman, R.H.; MacGillivray, L. Diversifying molecular and topological space via a supramolecular solid-state synthesis: A purely organic mok net sustained by hydrogen bonds. IUCrJ 2019, 6, 1032-1039. [CrossRef] [PubMed]

4. Oburn, S.M.; Santana, C.L.; Elacqua, E.; Groeneman, R.H. A diamondoid net sustained by halogen bonds: Employing a cyclobutane to generate a tetrahedral architecture. CrystEngComm 2020, 22, 4349-4352. [CrossRef]

5. Cohen, M.D.; Schmidt, G.M.J. Topochemistry. Part I. A Survey. J. Chem. Soc. 1964, 1996-2000. [CrossRef] 
6. Quentin, J.; Swenson, D.C.; MacGillivray, L.R. Supramolecular Sandwiches: Halogen-Bonded Coformers Direct [2+2] Photoreactivity in Two-Component Cocrystals. Molecules 2020, 25, 907. [CrossRef]

7. Sinnwell, M.A.; MacGillivray, L.R. Halogen-Bond-Templated [2+2] Photodimerization in the Solid State: Directed Synthesis and Rare Self-Inclusion of a Halogenated Product. Angew. Chem. Int. Ed. 2016, 55, 3477-3480. [CrossRef]

8. Sinnwell, M.A.; Blad, J.N.; Thomas, L.R.; MacGillivray, L.R. Structural flexibility of halogen bonds showed in a single-crystal-tosingle-crystal [2+2] photodimerization. IUCrJ 2018, 5, 491-496. [CrossRef]

9. Bosch, E.; Battle, J.D.; Groeneman, R.H. Crystal structure and photoreactivity of a halogen-bonded cocrystal based upon 1,2-diiodoperchlorobenzene and 1,2-bis(pyridin-4-yl)ethylene. Acta Crystallogr. Sect. C Struct. Chem. 2020, 76, 557-561. [CrossRef]

10. Bosch, E.; Kruse, S.J.; Krueger, H.R., Jr.; Groeneman, R.H. Role of $\pi-\pi$ Stacking and Halogen Bonding by 1,4-Diiodoperchlorobenzene to Organize the Solid State to Achieve a [2 + 2] Cycloaddition Reaction. Cryst. Growth Des. 2019, 19, 3092-3096. [CrossRef]

11. Carrona, T.; Liantonio, R.; Logothetis, T.A.; Metrangolo, P.; Pilati, T.; Resnati, G. Halogen Bonding and $\pi \cdots \pi$ Stacking Control Reactivity in the Solid State. J. Am. Chem. Soc. 2004, 126, 4500-4501. [CrossRef] [PubMed]

12. Bosch, E.; Kruse, S.J.; Reinheimer, E.W.; Rath, N.P.; Groeneman, R.H. Regioselective [2 + 2] cycloaddition reaction within a pair of polymorphic co-crystals based upon halogen bonding interactions. CrystEngComm 2019, 21, 6671-6675. [CrossRef]

13. Papaefstathiou, G.S.; Friščić, T.; MacGillivray, L.R. A Regiocontrolled 'Head-to-Tail' [2+2] Photodimerization of a Stilbene involving a Ternary Solid based on Catechol. J. Supramol. Chem. 2002, 2, 227-231. [CrossRef]

14. Hamilton, T.D.; Papaefstathiou, G.S.; MacGillivray, L.R. A Polyhedral Host Constructed Using a Linear Template. J. Am. Chem. Soc. 2002, 124, 11606-11607. [CrossRef]

15. Grobelny, A.L.; Verdu, F.A.; Groeneman, R.H. Solvent-free synthesis and purification of a photoproduct via sublimation of a tetrahalogenated template. CrystEngComm 2017, 19, 3562-3565. [CrossRef]

16. Schmidt, G.M.J. Photodimerization in the solid state. Pure Appl. Chem. 1971, 27, 647-678. [CrossRef]

17. Hill, Y.; Briceño, A. Exploiting the use of hydrogen bonding and metal-coordination in the self-assembly of photoreactive multicomponent networks. Chem. Commun. 2007, 17, 3930-3932. [CrossRef]

18. Quentin, J.; MacGillivray, L.R. Halogen versus Hydrogen Bonding in Binary Cocrystals: Novel Conformation a Coformer with [2+2] Photoreactivity of Criss-Crossed C=C Bonds. ChemPhysChem 2020, 21, 154-163. [CrossRef]

19. Peedikakkal, A.M.P.; Vittal, J.J. Solid-State Photochemical [2+2] Cycloaddition in a Hydrogen-Bonded Metal Complex Containing Several Parallel and Crisscross C-C bonds. Chemistry 2008, 14, 5329-5334. [CrossRef]

20. Nguyen, T.B.; Nguyen, T.M.; Retailleau, P. [2+2] Photodimerization of Stilbazoles Promoted by Oxalic Acid in Suspension. Chemistry 2020, 26, 4682-4689. [CrossRef]

21. Elacqua, E.; Kaushik, P.; Groeneman, R.H.; Sumrak, J.C.; Bučar, D.-K.; MacGillivray, L.R. A Supramolecular Protecting Group Strategy Introduced to the Organic Solid State: Enhanced Reactivity through Molecular Pedal Motion. Angew. Chem. Int. Ed. 2012, 51, 1037-1041. [CrossRef] [PubMed]

22. Harada, J.; Ogawa, K. Topics in Stereochemistry; Denmark, S.E., Siegel, J.S., Eds.; Wiley: Chichester, UK, 2006; Volume 25, pp. 31-47.

23. Harada, J.; Ogawa, K. Invisible but Common Motion in Organic Crystals: A Pedal Motion in Stilbenes and Azobenzenes. J. Am. Chem. Soc. 2001, 123, 10884-10888. [CrossRef] [PubMed]

24. Harada, J.; Ogawa, K.; Tomoda, S. The Central Bond Length in 1,2-Diphenylethanes. J. Am. Chem. Soc. 1995, 117, 4476-4478. [CrossRef]

25. Ogawa, K.; Sano, T.; Yoshimura, S.; Takeuchi, Y.; Toriumi, K. Molecular structure and intramolecular motion of (E)-stilbenes in crystals. An interpretation of the unusually short ethylene bond. J. Am. Chem. Soc. 1992, 114, 1041-1051. [CrossRef]

26. Harada, J.; Ogawa, K.; Tomoda, S. Molecular Motion and Conformational Interconversion of Azobenzenes in Crystals as Studied by X-ray Diffraction. Acta Crystallogr. Sect. B 1997, 53, 662-672. [CrossRef]

27. Harada, J.; Ogawa, K. Ethane Bond Length in 1,2-Diphenylethanes. Struct. Chem. 2001, 12, 243-250. [CrossRef]

28. Harada, J.; Ogawa, K. X-ray Diffraction Analysis of Nonequilibrium States in Crystals: Observation of an Unstable Conformer in Flash-Cooled Crystals. J. Am. Chem. Soc. 2004, 126, 3539-3544. [CrossRef]

29. Harada, J.; Harakawa, M.; Ogawa, K. Conformational Change of N-Benzylideneamines in Crystals. Acta Cryst. 2004, B60, 589-597. [CrossRef]

30. Ohba, S.; Hosomi, H.; Ito, Y. In Situ X-ray Observation of Pedal-like Conformational Change and Dimerization of transCinnamamide in Cocrystals with Phthalic Acid. J. Am. Chem. Soc. 2001, 123, 6349-6352. [CrossRef]

31. Gero, A.; Markham, J.J. Studies on Pyridines: I. The Basicity of Pyridine Bases. J. Org. Chem. 1951, 16, 1835-1838. [CrossRef]

32. Macrae, C.F.; Bruno, I.J.; Chisholm, J.A.; Edgington, P.R.; McCabe, P.; Pidcock, E.; Rodriguez-Monge, L.; Taylor, R.; van de Streek, J.; Wood, P.A. Mercury CSD 2.0-New Features for the Visualization and Investigation of Crystal Structures. J. Appl. Cryst. 2008, 41, 466-470. [CrossRef]

33. Otwinowski, Z.; Minor, W. Processing of X-ray diffraction data collected in oscillation mode. Methods Enzymol. 1997, 276, 307-326. [PubMed]

34. Sheldrick, G.M. SHELXT-Integrated space-group and crystal-structure determination. Acta Crystallogr. A Found Adv. 2015, A71, 3-8. [CrossRef] [PubMed]

35. Sheldrick, G.M. Crystal structure refinement with SHELXL. Acta Crystallogr. Sect. C Struct. Chem. 2015, 71, 3-8. [CrossRef] [PubMed] 
36. Dolomanov, O.V.; Bourhis, L.J.; Gildea, R.J.; Howard, J.A.K.; Puschmann, H. OLEX2: A complete structure solution, refinement and analysis program. J. Appl. Crystallogr. 2009, 42, 339-341. [CrossRef]

37. Spek, A.L. Structure validation in chemical crystallography. Acta Crystallogr. Sect. D Biol. Crystallogr. 2009, 65, 148-155. [CrossRef] 